\title{
NEW EVIDENCE FOR A CHANGE IN PHYSICAL CONDITIONS AT DEPTHS NEAR 100 KILOMETERS*
}

By B. Gutemperg and Charles F. Rtchter.

Comparative investigation of the seismograms of shallow earthquakes shows that the amplitudes of the first recorded longitudinal wave $\left(\mathrm{P}_{\mathrm{n}}\right.$ or $\left.\mathrm{P}\right)$ vary considerably with distance from the epicenter. ${ }^{1}$ At distances up to $6^{\circ}$ the seismograms are of "local shock" type, and the amplitude of $P_{n}$ increases somewhat with distance. From $6^{\circ}$ the amplitude decreases regularly, reaching a very small minimum near $14^{\circ}(1500 \mathrm{~km}$.). There is then a sudden increase, and the amplitudes continue large to beyond $20^{\circ}$. Together with the corresponding travel times, this suggests that at about $80 \mathrm{~km}$. below the surface the velocity of longitudinal waves ceases to increase with depth, and probably decreases slightly through a limited range of depth, below which it again increases with depth. It is not yet settled whether the decrease is gradual throughout its range, or whether it takes place suddenly at a discontinuity.

Additional information bearing on this problem can be derived from a study of seismograms of deep shocks recorded at short distances. No such seismograms are written at Pasadena or the other stations in California, since the nearest source of such earthquakes is at a distance of about $19^{\circ}$. However, we are fortunate in having at Pasadena the complete file of seismograms written at Huancayo, Peru, down to July, 1937. We are greatly indebted to the Carnegie Institution of Washington for maintaining this station and making the original seismograms available at Pasadena. Without the Huancayo file, this paper, and much other fruitful research, would have been impossible.

Among the earthquakes recorded at Huancayo are a considerable number at depths ranging from 50 to $250 \mathrm{~km}$., at distances covering the whole critical range. Many of these are large enough to be recorded at Pasadena or other distant stations, so that depth and epicenter can be determined reliably. Table 1 lists these shocks in chronological order. The first column gives the catalogue number assigned to each shock in other publications by the writers. ${ }^{2}$ The date and hour of occurrence, the geographical coordinates of the epicenter, and the depth of focus in kilometers, follow in order. The next column contains letters indicating the quality of the determination of epicenter, origin time, and depth, in the order named. A means very accurate (epicenter probably good within 1 degree, depth within $30 \mathrm{~km}$.); B, good (within 2 deg. and $50 \mathrm{~km}$.); C, fair. The next column gives the distance, $\Delta$, from Huancayo in degrees, and

* Manuscript received for publication June 23, 1939.

'B. Gutenberg and C. F. Richter, "On Seismic Waves" (second paper), Gerlands Beitr. 2. Geophysik, 45:280-360 (1935); see esp. pp. $337 \mathrm{ff}$.

${ }^{2}$ B. Gutenberg and C. F. Richter, "Depth and Geographical Distribution of Deep-focus Earthquakes," Bull. Geol. Soc. Am., 49:249-288 (1938); a second paper under same title, ibid., 50:1511-1528 (1939.) 
TABLE 1

Data for Shocks Used

\begin{tabular}{|c|c|c|c|c|c|c|c|c|c|}
\hline \multirow[b]{2}{*}{ No. } & \multirow{2}{*}{\multicolumn{3}{|c|}{ Date, hour }} & \multicolumn{3}{|c|}{ Origin } & \multirow[b]{2}{*}{ Qual. } & \multirow{2}{*}{$\stackrel{\Delta}{\Delta}$ (deg.) } & \multirow[b]{2}{*}{ Ampl. of $\mathrm{F}$} \\
\hline & & & & Lat. & $\begin{array}{l}\text { Long. } \\
\text { (west) }\end{array}$ & $\underset{(\text { Depth. }}{(\mathrm{km} .)}$ & & & \\
\hline \multicolumn{10}{|c|}{1933} \\
\hline $18 \mathrm{~m}$ & Feb. & 10 & $8^{h}$ & 23 & 68 & 110 & $\mathrm{CCB}$ & $123 / 4$ & $\mathrm{c}$ \\
\hline $11 \mathrm{c}$ & Aug. & 9 & 23 & $151 / 2$ & $681 / 4$ & 170 & BBB & $71 / 2$ & c \\
\hline 17 & Oct. & 25 & 23 & 23 & $663 / 4$ & 220 & AAA & $133 / 4$ & $\mathrm{~d}$ \\
\hline $24 \mathrm{a}$ & Nov. & 14 & 14 & 32 & $691 / 2$ & 110 & $\mathrm{BAA}$ & 21 & $d$ \\
\hline \multicolumn{10}{|c|}{1934} \\
\hline 16 & June & 24 & 5 & 22 & $681 / 2$ & 110 & $\mathrm{BAA}$ & $12 \frac{1}{4}$ & $\mathrm{e}$ \\
\hline $13 p$ & Dec. & 4 & 17 & $191 / 2$ & $691 / 2$ & 130 & $\mathrm{BBC}$ & $91 / 2$ & a \\
\hline $15 \mathrm{a}$ & Dec. & 23 & 9 & & 68 & 100 & BBA & $121 / 2$ & $\mathrm{c}$ \\
\hline \multicolumn{10}{|c|}{1935} \\
\hline $23 \mathrm{i}$ & Feb. & 13 & 17 & $251 / 2$ & 69 & 100 & $\mathrm{BAA}$ & 15 & $\mathrm{c}$ \\
\hline $17 \mathrm{~m}$ & Feb. & 28 & 7 & 23 & 67 & 200 & $\mathrm{CCC}$ & 14 & $d$ \\
\hline $8 \mathrm{~m}$ & Mar. & 8 & 11 & & 80 & 100 & $\mathrm{CCC}$ & 9 & $\mathrm{a}$ \\
\hline $10 \mathrm{~d}$ & Mar. & 9 & 2 & 12 & 78 & 150 & $\mathrm{CCC}$ & 3 & $\mathrm{e}$ \\
\hline $11 r$ & Mar. & 26 & 19 & $15 \frac{1}{2}$ & 73 & 120 & BBB & 5 & $\mathrm{~b}$ \\
\hline $5 \mathrm{k}$ & Sept. & 18 & 4 & $51 / 2 \mathrm{I}$ & 76 & 80 & $\mathrm{BBB}$ & $171 / 2$ & e \\
\hline $11 \mathrm{~d}$ & Sept. & 19 & 9 & $15 \frac{1}{1 / 2}$ & 70 & 250 & $\mathrm{BCB}$ & $61 / 2$ & d \\
\hline $21 \mathrm{i}$ & Sept. & 28 & 4 & 24 & 67 & 150 & $\mathrm{CCC}$ & 14 & c \\
\hline $5 q$ & Oct. & 27 & 22 & 41 & 76 & 150 & $\mathrm{BCB}$ & 16 & $\mathrm{~d}$ \\
\hline $8 \mathrm{e}$ & Nov. & 2 & 21 & 2 & 79 & 130 & $\mathrm{CCC}$ & 10 & $\mathrm{a}$ \\
\hline \multicolumn{10}{|c|}{1936} \\
\hline $16 \mathrm{~d}$ & Jan. & 31 & 15 & 22 & 67 & 160 & $\mathrm{CCC}$ & 14 & $\mathrm{c}$ \\
\hline $23 r$ & April & 30 & 17 & 31 & 67 & 200 & $\mathrm{BBB}$ & 21 & $\mathrm{c}$ \\
\hline $8 \mathrm{r}$ & May & 6 & 3 & 8 & 75 & 160 & $\mathrm{BBA}$ & 3 & d \\
\hline $16 r$ & June & 22 & 10 & 22 & 68 & 90 & $\mathrm{CBA}$ & 12 & a \\
\hline $12 \mathrm{r}$ & July & 4 & 8 & 18 & 70 & 140 & $\mathrm{BBA}$ & $81 / 2$ & a \\
\hline $12 \mathrm{~m}$ & Sept. & 16 & 17 & 16 & $72 \frac{1}{2}$ & 130 & BBA & $51 / 2$ & $d$ \\
\hline $20 \mathrm{~m}$ & Nov. & 7 & 5 & 24 & 66 & 200 & $\mathrm{CCC}$ & $151 / 2$ & b \\
\hline 171 & Nov. & 7 & 6 & 23 & 67 & 200 & $\mathrm{BBB}$ & 14 & b \\
\hline $16 \mathrm{~m}$ & Nov. & 29 & 14 & $221 / 2$ & 67 & 230 & $\mathrm{BCC}$ & $131 / 2$ & $\mathrm{c}$ \\
\hline $13 \mathrm{~s}$ & Dec. & 5 & 0 & 20 & $701 / 2$ & 100 & $\mathrm{BBA}$ & 10 & a \\
\hline $23 \mathrm{~m}$ & Dec. & 19 & 2 & $281 / 2$ & $681 / 2$ & 160 & $\mathrm{CCB}$ & $171 / 2$ & $\mathrm{e}$ \\
\hline \multicolumn{10}{|c|}{1937} \\
\hline $24 r$ & Jan. & 30 & 10 & 36 & 72 & 100 & $\mathrm{CCB}$ & 23 & $c$ \\
\hline $24 \mathrm{~m}$ & Feb. & 12 & 18 & & $661 / 2$ & 200 & $\mathrm{BBB}$ & $211 / 2$ & $c$ \\
\hline $17 \mathrm{k}$ & Feb. & 24 & 18 & 23 & 67 & 260 & $\mathrm{CCC}$ & 14 & a \\
\hline $23 \mathrm{~d}$ & Mar. & 14 & 11 & $241 / 2$ & $691 / 2$ & 60 & $\mathrm{BBA}$ & 14 & $\mathrm{c}$ \\
\hline $23 p$ & Mar. & 19 & 18 & 29 & 70 & 70 & $\mathrm{BCB}$ & 18 & $d$ \\
\hline $10 \mathrm{p}$ & Mar. & 28 & 12 & $131 / 2$ & 75 & 120 & $\mathrm{CCC}$ & 2 & $\mathrm{c}$ \\
\hline $11 \mathrm{~m}$ & Mar. & 29 & 7 & $151 / 2$ & 71 & 120 & $\mathrm{BBA}$ & 6 & $\mathrm{c}$ \\
\hline $6 \mathrm{~m}$ & May & 21 & 13 & $21 / 2$ & $771 / 2$ & 90 & $\mathrm{AAA}$ & $141 / 2$ & $\mathrm{c}$ \\
\hline $12 \mathrm{k}$ & July & 9 & 17 & 16 & 72 & 180 & $\mathrm{BCC}$ & $51 / 4$ & $\mathrm{~d}$ \\
\hline $7 \mathrm{~m}$ & July & 19 & 19 & $1 \frac{1}{2}$ & $761 / 2$ & 190 & $\mathrm{AAA}$ & $101 / 2$ & d \\
\hline
\end{tabular}


the final column indicates the amplitude of the recorded $\mathrm{P}$ waves, relative to the shock as a whole. This is not merely a measure of the size and sharpness of the initial $\mathrm{P}$ at Huancayo, as the magnitude of the shock, as indicated by the seismograms at Pasadena, has also been considered. The following scale is used: a, very small; b, small; c, medium; $d$, large; e, very large.

It should be noted that the distance from Huancayo is usually known more

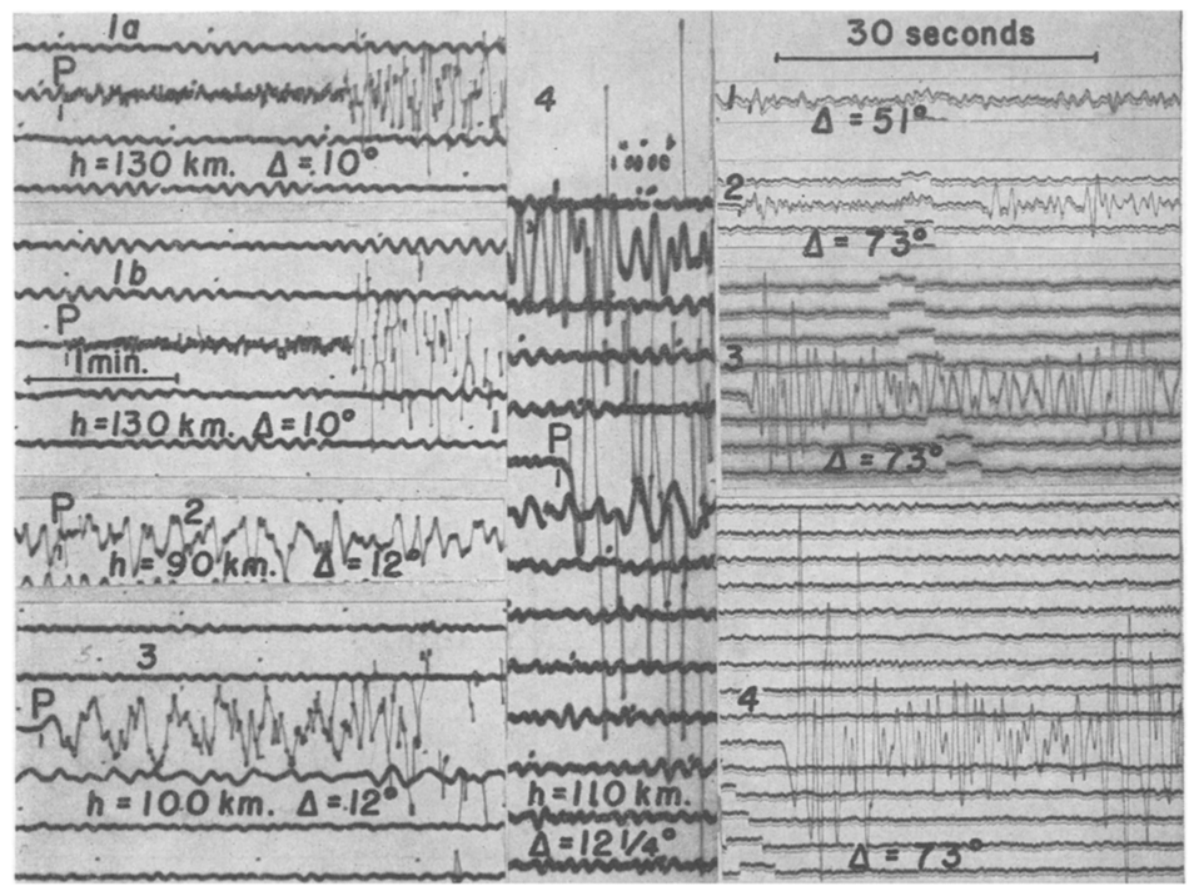

Fig. 1. Left and center: Records of Huancayo, Peru, Wenner pendulum ( $1 a$ and 4, N-S; $1 b, 2$ and $3, \mathrm{E}-\mathrm{W})$. Right: Records of short-period Benioff vertical, Pasadena. 1, November $2,1935,21^{\mathrm{h}} ; 2$, June $22,1936,10^{\mathrm{h}} ; 3$, December $23,1934,9^{\mathrm{h}} ; 4$, June 24, 1934, $5^{\mathrm{h}}$. The Huancayo record 2 is masked by microseisms.

precisely than is indicated by the quality assigned to the epicenter. As an example, a special comparative investigation of shocks 16 and $16 \mathrm{r}$ shows that the latter is $20 \mathrm{~km}$. shallower than the former (with an error probably not exceeding $5 \mathrm{~km}$.), and possibly about $1 / 4 \mathrm{deg}$. to the north.

A few characteristic seismograms are reproduced in figure 1.

The data of table 1 are represented graphically in figure 2 . The usual results for normal shocks at short distances in other regions are indicated by symbols plotted for a depth of $20 \mathrm{~km}$.

It is evident from inspection of the figure that abnormally small amplitudes occur within a limited region of the plot. Large amplitudes occur immediately 
outside; but the observations are not yet sufficient to permit our drawing the bounding curve with confidence. Alternative possibilities have been indicated in the figure. The limiting depth, below which there is no distance at which these small amplitudes are observed, is probably at about 150 to $200 \mathrm{~km}$.

In interpreting the figure it should be considered that relatively small amplitudes of $\mathrm{P}$ may be observed, more or less sporadically, at almost any dis-

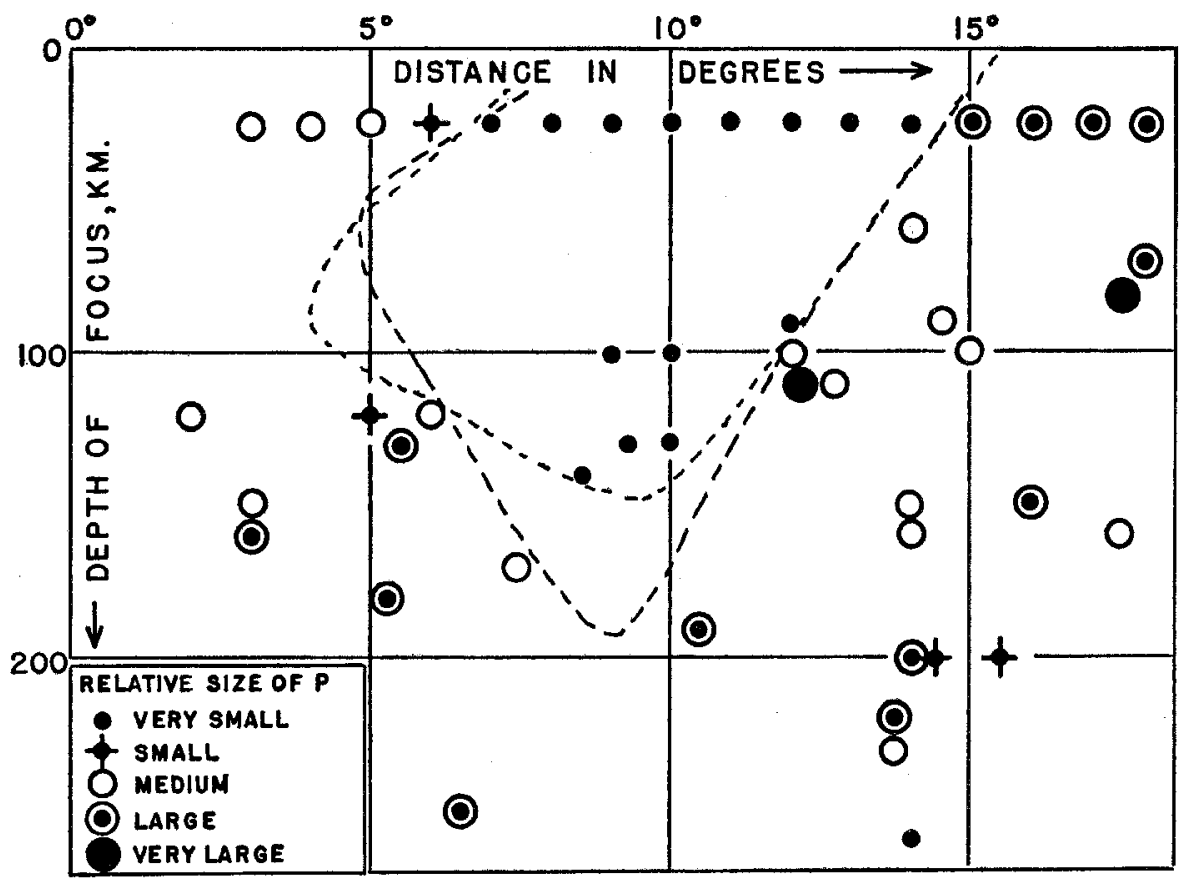

Fig. 2. Relative size of $\mathrm{P}$ on Huancayo, Peru, records as a function of focal depth and distance.

tance or depth; for it is known that the radiation of energy from the source leads to a definite distribution of initial compression or dilatation in zones and segments, and on the nodal boundary between regions of compression and regions of dilatation the observed amplitudes of $\mathrm{P}$ are small. Moreover, the partition of radiated energy between longitudinal and transverse waves may vary widely in different shocks. If we eliminate these more or less accidental circumstances, the data presented in figure 2 exhibit a phenomenon which is best explained in terms of the distribution of velocity with depth. The results are consistent with, and serve to confirm, the conclusion drawn from observations of shallower earthquakes, that there is a slight decrease in velocity with depth, at a level about $80 \mathrm{~km}$. below the surface. However, it is not yet possible to settle whether this decrease is gradual or discontinuous. 
To clarify discussion, a detailed theoretical investigation has been carried out for a hypothetical ideal case. We assume two layers, within each of which the velocity is constant, being smaller in the lower layer; the layers are assumed to be separated by a discontinuity. In figure 3 , sketches are presented for three different depths of focus. In $a$, the focus $\mathrm{F}$ is at the surface. With decreasing

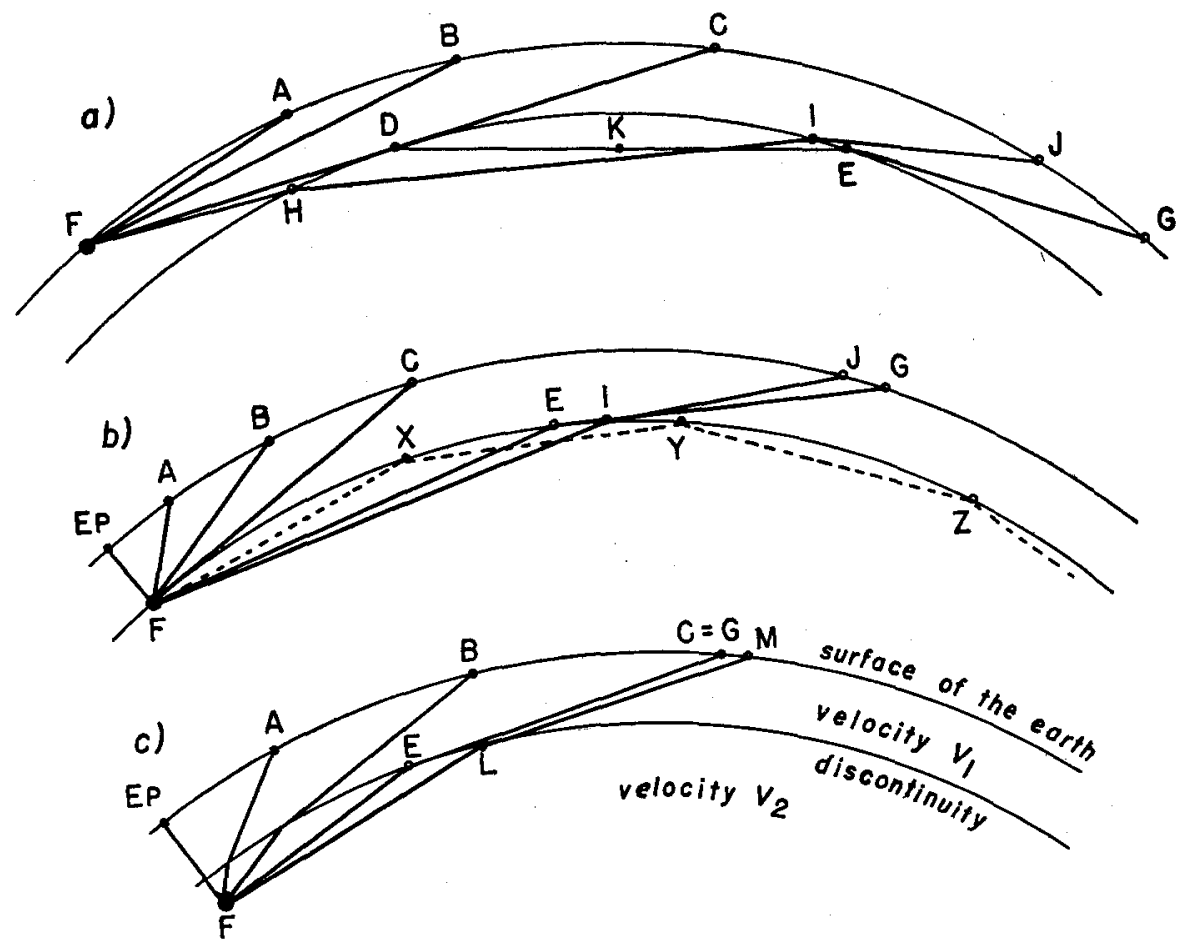

Fig. 3. Wave paths for three different focal depths in a sphere having a crustal layer with constant velocity $V_{1}$ and a deeper layer with constant velocity $V_{2}<V_{1}$.

angle of incidence, the rays reach the surface successively at $\mathrm{A}, \mathrm{B}$, and $\mathrm{C}$. The ray to $\mathrm{C}$ is tangent to the discontinuity at the point $\mathrm{D}$. From $\mathrm{D}$ the first ray through the discontinuity is refracted to $\mathrm{E}$, and reaches the surface at $\mathrm{G}$. With slightly decreasing angle of incidence, rays of type FHIJ result, reaching the surface at points nearer than $\mathrm{G}$. The minimum distance reached by these rays is a focal distance (a caustic). Between this and $\mathrm{C}$ is a shadow zone. With still smaller angles of incidence the distance of emergence to the surface again increases.

In $b$, the hypocenter $\mathrm{F}$ is at the discontinuity. The initial point of the shadow zone, $\mathrm{C}$, has moved to half the distance at which it occurs in $a$. This remains correct even if the velocity increases with depth in the upper layer. Hence, in 
figure 2 the initial distance of the shadow zone of small amplitudes may be expected to decrease with increasing hypocentral depth in the manner suggested by the dotted curves. In $b$ the tangent ray $\mathrm{FC}$ is followed by rays of the type FXYZ, which are repeatedly reflected totally from the inner face of the discontinuity, and never emerge into the upper layer. The first ray which again enters the upper layer is FEG, where EG is tangent to the discontinuity. As in $a$, the distance of emergence decreases for immediately following rays, such as FIJ, and then increases. Again there are a minimum distance, which determines a focus, and a shadow zone.

In $c$, the hypocenter is at a depth equal to that of the deepest point, $K$,

TABLE 2

Calculated Values

\begin{tabular}{|c|c|c|c|c|}
\hline \multirow{2}{*}{ Focus at } & \multicolumn{2}{|c|}{ Shadow zone } & \multirow{2}{*}{ Width } & \multirow{2}{*}{ Observed width } \\
\hline & Beginning & End & & \\
\hline 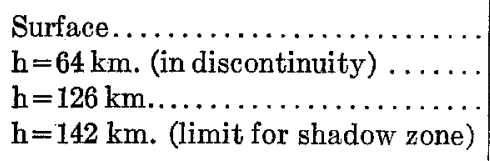 & $\begin{array}{c}16^{\circ} \\
8^{\circ} \\
13^{\circ} \\
\left(17^{\circ} 2\right)\end{array}$ & $\begin{array}{l}291 / 2^{\circ} \\
24^{\circ} \\
20^{\circ} \\
\left(17^{\circ} 2\right)\end{array}$ & $\begin{array}{l}1312^{\circ} \\
16^{\circ} \\
7^{\circ} \\
0^{\circ}\end{array}$ & $\begin{array}{l}8^{\circ} \pm \\
5^{\circ} \pm\end{array}$ \\
\hline
\end{tabular}

reached by the critical ray FDEG in $a$. This is the limiting depth of focus for the occurrence of a shadow zone. At this hypocentral depth the points $\mathrm{C}$ and $\mathrm{G}$ coincide. Successive rays emerge continuously through the range $\mathrm{ABC}$, and also continuously through the range GM . . ; but if $\phi$ is the angle of incidence at $F$, and $\Delta$ is the distance of emergence, then $\partial \Delta / \partial \phi$ has a discontinuity at $C$; its absolute value approaches 2 over the range $A B C$, and approaches zero over the range from $M$ toward $G$. The last result makes $G$ a focal point.

Numerical calculations have been carried out assuming velocities of 8.0 $\mathrm{km} / \mathrm{sec}$. in the upper layer, $7.9 \mathrm{~km} / \mathrm{sec}$. in the lower layer, and a depth for the discontinuity of 0.01 of the radius of the earth. The critical values then are as shown in table 2.

The calculated beginning of the shadow zone is at much larger distances than the observed beginning. This is principally due to the increase in velocity with depth in the upper layer. The limiting depth and the widths of the shadow zone are of the right order of magnitude. This indicates that an assumed decrease in velocity, at a depth of about $70 \mathrm{~km}$., from 8.0 to $7.9 \mathrm{~km} / \mathrm{sec}$. , would provide a fairly close representation of the observations. This agrees with the results from integrating observed travel-time curves. However, calculation must take account of the resumption of an increase in velocity with depth, which begins very gradually between $100 \mathrm{~km}$. and $200 \mathrm{~km}$. below the surface. This is indicated by travel times as well as amplitudes. 
EVIDENCE FOR A CHANGE IN PHYSICAL CONDITIONS AT 100 KILOMETERS 537

It should be noticed again that the observations do not unequivocally demand the existence of a discontinuity; for if the velocity merely decreases continuously with depth at a rate more rapid than about $0.01 \mathrm{~km} / \mathrm{sec}$. in $8 \mathrm{~km}$., the travel-time curve will be interrupted. Observations of travel times alone cannot decide the question, since under the various permissible assumptions the calculated travel times do not differ by more than a small fraction of a second.

According to Daly, ${ }^{3}$ a decrease in velocity from about 8.0 to $7.9 \mathrm{~km} /$ sec. at a depth of about $60 \mathrm{~km}$. can be explained as due to a transition from the crystalline to the vitreous state.

\section{SUMMARY}

Seismograms of South American earthquakes at depths down to $260 \mathrm{~km}$. recorded at Huancayo, Peru, are used to confirm and extend the conclusion that a slight decrease in the velocity of longitudinal waves occurs at a depth of about $80 \mathrm{~km}$.

\section{Sexsmologrcal Laboratort, Pasadena, Caltfornta.}

[Balch Graduate School of the Geological Sciences, California Institute of Technology, Contribution no. 277.]

\footnotetext{
${ }^{3}$ R. A. Daly, "The Depths of the Earth," Bull. Geol. Soc. Am., 44:243-264 (1933).
} 